\title{
Effectiveness of Relaxation Exercise on Work Stress Among IT Professionals
}

\author{
Dr.D.Suresh ${ }^{1} \&$ Dr.Suja Suresh ${ }^{2}$ \\ ${ }^{1}$ Dean, Occupational Therapy, Trichy SRM Medical College Hospital \& Research Centre, Samayapuram, Trichy. Email: sureshdevaraj1991@gmail.com \\ ${ }^{2}$ Vice principal, SRM Trichy College of Nursing.
}

DOI: 10.38177/AJAST.2020.4203

Study was conducted to investigate effectiveness of relaxation exercise on work stress among IT professionals working in selected private company. Main objective of the study was to determine the effectiveness of relaxation and stretching exercise on stress among IT professional. One group pretest posttest experiment design was adopted. 240 samples were selected to participate through convenient sampling method. Data was collected with work stress scale then the progressive relaxation and stretching exercise was demonstrated by the researcher then the samples were motivated to practice relaxation exercise for period of 4 weeks, there were supervised by research assistants. End of the $4^{\text {th }}$ week post test was conducted with same scale. Study was analyzed with descriptive and inferential statistics. Study explicated that there was statistically significant reduction in the stress level among IT professionals after the practice of relaxation and stretching exercise.

Keywords: Relaxation exercise, Stress

\section{Introduction}

Stress is part of everyday life. It can be negative or positive, keeping stress a manageable level is a lifelong process $^{1}$. In India nearly 6 million computer users have stress ${ }^{2}$. Indeed stress has a firm place in modern lexicon as I pods, CDs, people use the term casually to describe wide range of aches and pains resulting from our hectic phase of work and domestic life ${ }^{3}$. Stress related to work place is considered to be $2^{\text {nd }}$ most related to ill health. Work related stress not only cause sick but also increases absence or high turnover among workers, thereby reduce the performance in the organization ${ }^{4}$. Hence the organizations have the responsibility to manage work pressure experienced by their employee in a changing work place culture.

The following three appropriate strategies provide comprehensive framework in handling the stress, stress reduction, stress management and workplace counseling ${ }^{5}$. Stress related to work, employees undergo huge stress to perform better than their colleagues to meet their deadlines. Most of their job is target oriented; if targets are not met they may end up with stress and anxiety. Mostly they are not having social life and the time to spend with family is very less. This lack of recreation eventually ends up in stress and frustration ${ }^{6}$.

No one can avoid stress but you can counteract its detrimental effects by learning how to produce adaptive response. This puts the breaks on stress and brings your body and mind into state of equilibrium. Relaxation brings energy and heightens problem solving ability, boost motivation and productivity. Jacobson's progressive muscle relaxation technique is simple exercise to manage stress, it is cost effective method for professional to control and reduce their stress perception. It can be practiced for $10-15$ minutes per day ${ }^{7}$.

In IT field professional convert each second into Dollars, hence in this context the progression relaxation technique can be practiced in any position like sitting or lying. So the investigator was interested to study the effectiveness of Jacobson's progressive muscle relaxation technique and stretching exercise in reducing stress among IT professionals in selected IT company. 


\section{Objectives}

Assess existing level of work stress among IT professionals.

Effectiveness of relaxation and stretching exercise on work stress among IT professionals.

Associate the pretest stress level among IT professionals with the base line variables.

\section{Hypothesis}

There is significant difference in the pretest and posttest level of stress among IT professionals at $p<0.05$ level.

\section{Research Literature}

Review of literature was done on following headings.

Work stress and its effects on IT professionals.

Effectiveness of intervention strategies on stress management among IT professionals.

\section{Methodology}

\subsection{Research Approach and Design:}

Quantitative approach - pre experimental one group pretest posttest only design.

\subsection{Variables:}

5.2.1 Independent Variables: Jacobson's progressive muscle relaxation technique and stretching exercise.

5.2.2 Dependent Variables: Work stress of IT professionals.

\subsection{Setting:}

The study was conducted in selected IT Company in Trichy. The IT Company had 310 employees out of which 240 participated in the study.

5.4. Target Population: IT professionals.

5.5. Assessable Population: IT professionals in selected IT Company in Trichy.

5.6 Samples: IT professionals who fulfill the inclusion criteria who are working in selected IT Company,

5.6.1 Sample size: 240

5.6.2 Sampling Technique: Non probability - consecutive sampling technique

\subsection{Sampling Criteria:}

\subsubsection{Inclusion Criteria}

Professionals who are working for 8 hours in front of computers everyday

Willing to participate in the study 


\subsubsection{Exclusion Criteria}

Workers on leave and sick

Workers who were already following stress management strategies

\section{Data Collection Tool}

6.1 Section A: Base line variables (age, gender, type of family, marital status, working pattern, experience).

6.2 Section B: Stress assessment with work stress scale (WSS). It is standardized tool consist of 54 items with 6 domains. It has reliability of 0.9 and has been widely used Indian studies. Scoring range from $0-4$, with 0 indicating no stress, 1- mild stress, 2- moderate stress, 3 - sever stress, 4- extreme stress. Total score is 136 . Score interpretation: $1-33=$ mild stress, $34-67=$ moderate stress, $68-101=$ severe stress, $102-136=$ extreme stress.

\section{Data Collection Procedure}

Informed concern was obtained from the participants after getting from higher authorities. The researcher introduced themselves to the participants. Pretest was conducted for the duration of 30-40 minutes and the participants were asked to fill up WSS scale. They were divided into 3 groups and Jacobson's progressive relaxation (JPR) technique and stretching exercise was demonstrated to the group. It took $30-40$ minutes for the researcher to demonstrate the relaxation technique and stretching exercise. They were asked to practice for 20 minutes daily for the period of 4 weeks. They were asked to maintain self-assessment checklist to maintain regular follow up. At the end of $4^{\text {th }}$ week, post-test was conducted using same WSS scale. Every week follow up was done and reinforcement was given by the researchers.

\section{Data Analysis}

Descriptive statistics like frequency, percentage, mean and standard deviation were used. Inferential statistics like pared $t$ test and chi square was used. Pared $t$ test was used to find the effectiveness of the relaxation technique on work stress. Chi square was used to find out the association of selected baseline variables with stress.

\section{Results and Discussions}

\subsection{Section A: Back ground variables of samples}

Background variables of samples revealed that with regard to age, majority (49\%) of them were in age group of 23 to 27 years, $66 \%$ of participants were unmarried. Most of them(63\%) of them belong to nuclear family and evidence show that $52 \%$ were having less than 1 year of work experience. $72 \%$ were having sleeping pattern of less than $6-7$ hours a day. All of them were working on shift basis.

9.2 Section B: Frequency and percentage distribution of pretest stress level of IT Professionals. N=240

\begin{tabular}{|l|c|c|}
\hline \multicolumn{1}{|c|}{ Level of stress } & Frequency & Percentage \\
\hline Mild level stress & 80 & 33 \\
\hline
\end{tabular}




\begin{tabular}{|c|c|c|}
\hline Moderate level stress & 96 & 40 \\
\hline Severe level stress & 59 & 25 \\
\hline Extreme level stress & 3 & 2 \\
\hline Total & $\mathbf{2 4 0}$ & $\mathbf{1 0 0}$ \\
\hline
\end{tabular}

Table 1 show that majority of the IT professionals experienced moderate level of stress (40\%), only $2 \%$ of professionals were having extreme level of stress.

\section{Effectiveness of JPR exercise among IT professionals}

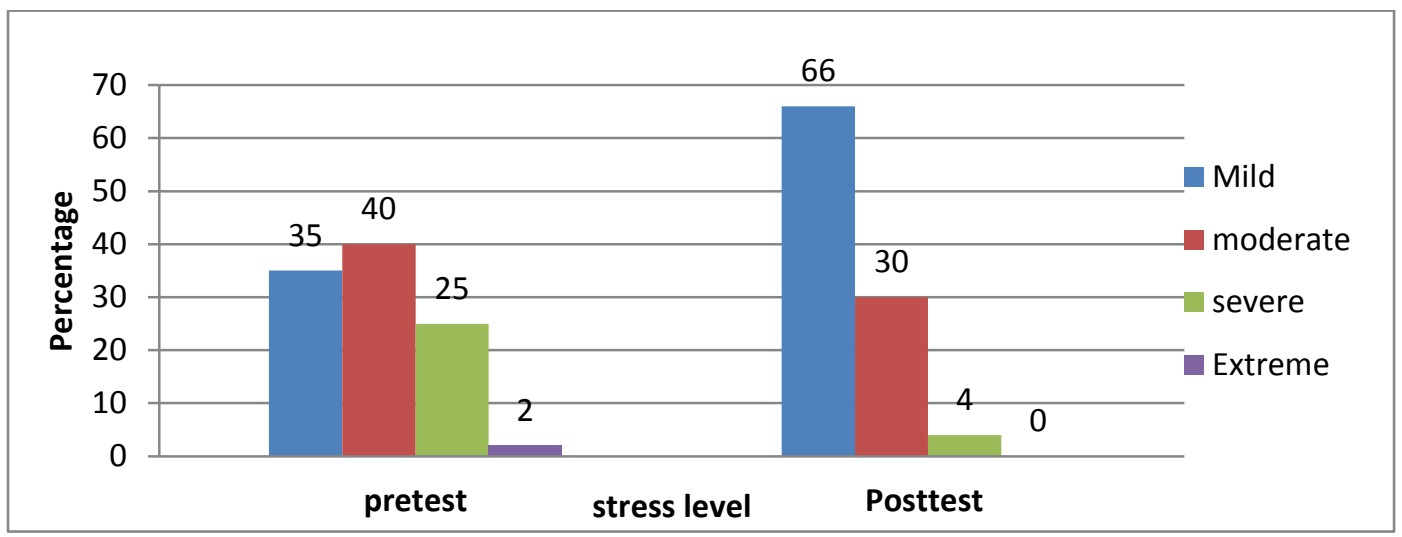

Figure 1: Pretest and posttest level of stress among IT professionals

Figure 1 shows the pretest level of stress among IT professionals. It showed that $2 \%$ of the professionals were having extreme level of stress and $40 \%$ were having moderate level of stress. Only $25 \%$ experienced severe level of stress. In the posttest none of them experienced extreme stress, 30\% experienced moderate level of stress, $66 \%$ of them experienced mild stress and $4 \%$ had severe level of stress. Figure 2 shows the Pretest and posttest mean stress score of the IT professionals with $\mathrm{N}=240$.

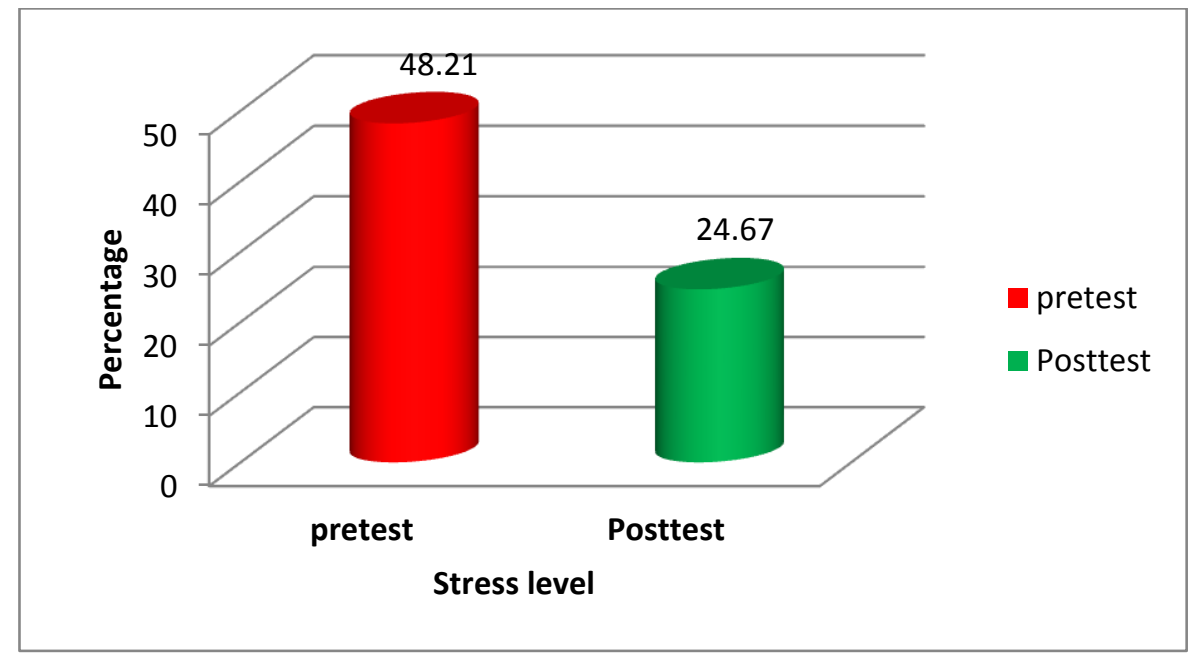

Figure 2: Pretest and posttest mean stress score of the IT professionals 
Figure 2 explicated that there was significant decrease in the mean stress score from pretest (48.21) to posttest (24.67).

Table 2: Effectiveness of Jacobson's progressive relaxation exercise among IT professionals. N=240

\begin{tabular}{|c|c|c|c|c|c|}
\hline Stress level & M & SD & MD & Pared t & p value \\
\hline Pretest & 48.21 & 23.36 & 23.54 & $13.14 * * *$ & 0.001 \\
\hline Posttest & 24.67 & 11.71 & & & \\
\hline
\end{tabular}

Table 2 shows that the mean stress among IT professionals was reduced to 24.67 during posttest after intervention. It was found to be significant with $t$ value of 13.147 at $p=0.001$ level. This shows that Jacobson's Progressive muscle relaxation training and stretching exercise was effective in reducing stress among It professionals.

\section{Discussion and Implication}

The Goal of the present study was to assess the level of work stress and effectiveness of Jacobson's progressive muscle relaxation training and stretching exercise in reducing the work stress. The findings of this present study revealed that out of 240 samples 33\% experienced mild level of stress, $40 \%$ experienced moderate level of stress, $25 \%$ experienced severe level of stress and $2 \%$ extreme level of stress during pretest. This finding is supported by study conducted by Priyanka.R in the year 2015, in her study found that $47 \%$ experienced moderate stress and $47 \%$ experienced mild stress among drivers ${ }^{8}$.

In the present study it was observed that the mean Posttest level of stress (24.67) was lesser than the mean pretest level of stress (48.21), which was significant at $\mathrm{p}<0.001$ level. This finding is supported by the study conducted by M.S. Palak, in 2014 on effectiveness of progressive muscle relaxation among staff nurses working in selected hospitals in Karnataka. Findings of study explicated that the relaxation training was effective in reducing the work stress level ${ }^{9}$.

Association of level of stress with baseline variables revealed that the junior IT professionals experienced more stress than senior IT professionals. This is supported by a study carried out by Jakkula.V, in 2012, found that the senior IT managers experienced less level stress compared to the junior IT professionals ${ }^{10}$. There is significant association between stress and duration of working hours among IT professionals. Long working hour increases stress among IT professional was observed.

\section{Implication of the Study}

Stress affects the efficiency of the person hence it is mandatory to provide conducive work environment support to maintain individuality in the work place. Workers need effective management of stressors by utilizing different strategies. The study revealed the significant difference in level of stress among the IT professionals before and after the intervention. The present study is eye opener to create awareness among IT professionals in stress minimizing technique in their day to day life. Stress can't be completely vanished in one's life but it can be well managed with proper lifestyle modification. 


\section{Conclusion}

The present study suggests that JPR training and stretching exercise is effective in reducing the work stress among IT professionals. Practicing proper stress management will be beneficial to the worker in maintaining their physical and mental health, and increase the productivity of the organization. This study recommended that similar study can be carried out with large samples.

\section{Conflict of Interest}

There is no conflict of Interest.

\section{Funding}

No source of funding is reported by the author.

\section{REFERENCES}

1. M.C.Townsend, Psychiatric mental health nursing $5^{\text {th }}$ ed. F.A. Davis company publication, Philadelphia, 2004.

2. Effects of prolonged use of computers on human health. 2001(1); retrieved from http:www.isam Indian.org/essay/cmccurrent/shtml.

3. C. Cooper, Stress and wellbeing at work, abstract of EFH; conference publication; 2008; Retrieved from http://: www.enterprise for health .org/ management -conference/ London- Oct.2008/conference publication.

4. National institute of occupational safety and health- stress at work (NIOSH publication) Washington, DC: US government printing office.

5.C.L. Cooper, Cartwright. S; Healthy organization- a practice approach to occupational stress. human relations.1994.41 (4); Retrieved from http;//Lun. Sage pub.com/content/47/4/48, abstract.

6. Sahana, Stress among IT professional leading to depression.April 29 2011,The Hindu,

7. E. Jacobson. Progressive relaxation, 2ndsdi.,Chicago: University of Chicago press;1938.64-68. Available from open med.nic.in/2132/01/e3.pdf.

8. R. Priyanka. etal, 2015. Effectiveness of relaxation technique to reduce stress among workers. International journal of science and research. 4, 867-8.

9. Palakpatel, 2014, study assess the effectiveness of progressive muscle relaxation among staff nurses working in selected hospitals. IOSR journal of nursing and health sciences, Vol.3, issue 3, pp 34-59.

10. V. Jakkula. Rao. Occupational Stress, mental health and coping among IT professionals. Indian journal of Occupational Environmental medcine.2012, 16(1). 